in-depth review of the SAM is performed every 5 years by members of the original development team, as well as by new additions to the group, with a goal of replacing at least one-third of the questions.

Finally, the commenting feature accessible to Diplomates after completing the SAM questions has also proven to be a helpful tool for keeping SAMs up to date. As with the hedges, staff members review this feedback on a regular basis. In addition to providing input regarding ambiguous or controversial content, these comments can also alert our staff to content that has become outdated because of new recommendations or studies.

After a physician has revised or replaced a question, the changes go to the Content Development department. The new or revised content is then edited and incorporated into the department's database. From there, the new content is exported to the IT department, where it is moved into another database. The editors then review the questions once more in the format used on the Web., Cnce approved, the changes are deployed to our website.

While complex and labor-intensive, these strategies have served to keep the SAMs current and assure our Diplomates that the content remains dynamically responsive to the changing field of family medicine! Micbael D. Hagen, MD, Martin A Quan, MDi Roger Fain, MA, William DeBord, MSLS

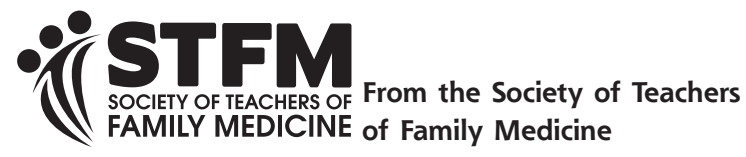

Ann Fam Med 2015;13:89-90. doi: 10.1370/afm.1749.

\section{STFM PREPARES FAMILY MEDICINE EDUCATORS TO LEAD}

There is a critical need for leadership development in family medicine. The Patient Protection and Affordable Care Act, the expansion of Medicaid in many states, and the aging population are driving the need for an expanded family medicine workforce. Medical schools and residency programs are jumping through hoops to educate a workforce to meet that need, in spite of the fact that health systems are incentivized to distribute Graduate Medical Education (GME) funding to subspecialty training. ${ }^{1-2}$

There is hope that the funding for both graduate medical education and primary care services may be changing. The nation is coming to realize that primary care must be at the foundation of a health care system that actually delivers better health, better health care, and lower costs. The July 2014 Institute of Medicine report, Graduate Medical Education That Meets the Nation's Health Needs, calls for changes to GME financing and governance to address deficiencies and shape the physician workforce for the future. Family medicine organizations introduced to Congress and the public new policy recommendations for graduate medical education. And Family Medicine for America's Health, a 20+ million dollar campaign launched in October 2014, is implementing strategies to ensure broad access to sustained, primary care relationships; reduce health care disparities; transform training; and facilitate a transition from fee-for-service payment to comprehensive payment. ${ }^{3-5}$

All of is happening as residency programs and fellowships are adjusting to changes in the graduate medical education accreditation process, including the transition to a single accreditation system.

Change such as this requires leadership from all of family medicine. Physicians, educators, researchers, and other health professionals need to be prepared to step up and advance change in programs, practices, institutions, and communities. "Leadership offers the enviable opportunity to influence the course of events: it direction, its content, and its texture," points out STFM President Sam Cullison, MD.

STFM is helping family medicine educators prepare to lead change and to lead in the midst of change. Two Leading Change task forces have been charged with developing and disseminating curriculum and resources to educate and empower family medicine faculty. The first launched a series of 12 free online modules. The second is working on:

- Curriculum for live presentations on topics such as Calibrating the Leader, Power and Politics of Change, Creative Leadership, and Building the Team. This curriculum will be tailored for established fellowships, conference/preconference workshops, and STFM On the Road presentations. The first training session will be at the 2015 STFM Annual Spring Conference.

- An indexed online toolkit that includes links to:

- References listed in the Leading Change online modules

- Worksheets, forms, and assessment tools to accompany the modules

- Recommended readings

- Case studies

- Previous fellowship projects

- A yearlong leading change fellowship that will offer mid- to senior-level faculty the opportunity to enhance their ability to lead change by applying the existing Leading Change curriculum to an actual change opportunity within their institutions 
or departments. The fellowship will be multidisciplinary and will likely include dyads. The fellowship is slated to launch at the 2015 Conference on Practice Improvement. STFM already has a yearlong Emerging Leaders Fellowship. The STFM Foundation coordinates a Bishop Fellowship Program for senior faculty.

\section{Leadership Training at the 2015 STFM Annual Spring Conference}

The 2015 Annual Spring Conference in Orlando will have a leadership theme and will include several sessions on leadership including a Family Medicine for America's Health Town Hall meeting, a callto-leadership general session presentation by Jeri Hepworth, $\mathrm{PhD}$, a luncheon training activity by the Leading Change Task Force, a presentation by Kavita Patel, MD, on the "Impact of the Affordable Care Act on Family Medicine, "speed mentoring" opportunities, and other leadership testimonials, activities, and recognition.

"One of our most important obligations as citizens, as health care professionals, and as human beings, is to leave the world better that we found it," observes Dr Cullison. "Leadership provides us with the opportunity to do that."

Mary Theobald, MBA

Vice President of Communications and Programs Society of Teachers of Family Medicine

\section{References}

1. American Academy of Family Physicians. Turning the ship on shortage of family physicians - improving medical education, filling the family physician pipeline. http://www.aafp.org/media-center/ kits/2012-match.html. Accessed Nov 26, 2014.

2. Wender R, Borkan J, Davis A; Association Of Departments Of Family Medicine. A pivotal time for family medicine leadership development. Ann Fam Med. 2011;9(2):182. 10.1370/afm.1236.

3. Institute of Medicine. Graduate medical education that meets the nation's health needs. http://www.iom.edu/Reports/2014/GraduateMedical-Education-That-Meets-the-Nations-Health-Needs.aspx. Accessed Dec 1, 2014.

4. Family medicine organizations ask congress to implement new policies for GME reform. STFM News. Sep 15, 2014. https://www.stfm. org/NewsJournals/STFMNews/NewsSeptember152014. Accessed Dec 1, 2014.

5. Phillips RL Jr, Pugno PA, Saultz JW, et al. Health Is primary: family medicine for america's health. Ann Fam Med. 2014;12(Suppl 1): S1-S12.

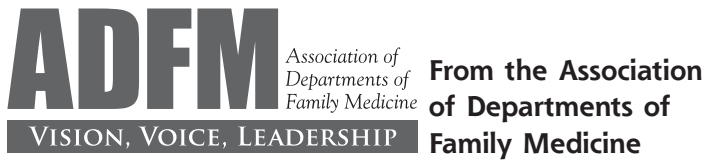

Ann Fam Med 2015;13:90-91. doi: 10.1370/afm.1748.

\section{INTERPROFESSIONAL EDUCATION: A WEBINAR FEATURING CASE EXAMPLES}

Interprofessional Education (IPE) is a goal many of us in academic medicine strive for, but the true outcome of training in a way that transcends disciplinary boundaries, both in the classroom and in in clinical environments, remains a challenge. ADFM held a webinar in September to address critical challenges of executing IPE, including: stakeholder buy-in, curriculum development $_{i}$ venues for teaching financing $_{i}$ relationship management ${ }_{i}$ defining roles and responsibilities of learners and teachers; and interface with regulatory bodies.

The roughly 30 webinar participants were equally split among family medicine department chairs, family medicine department administrators, family medicine faculty, and individuals in other academic roles. The majority (62\%) were from allopathic medical schools, with another $15 \%$ each from Large Regional Medical Centers or "other" settings, and the final $8 \%$ from academic health center residency programs. The vast majority (91\%) had IPE as part of the curriculum with the majority of these experiences noted as a combination of elective and required. Over three-quarters of participants reported that they were directly involved in IPE at their home institutions.

The webinar was moderated by Denise Rodgers, MD, Vice Chancellor for Interprofessional Programs at Rutgers Biomedical and Health Science, and featured innovative IPE case studies from 4 institutions, presented by professionals representing family medicine, pharmacy, and nursing: Christine Arenson, MD and Christine Jerpbak, MD, Sidney Kimmel Medical College, Thomas Jefferson University; Brian Prestwich, MD, Keck School of Medicine of University of Southern California; Dan Mickool, MS, RPh, University of New England ${ }_{i}$ Carolyn Rutledge, PhD, FNP-BC, Old Dominion University.

In addition to addressing the common list of challenges, each presenter described the numbers and types of students and residents participating in the IPE, as well as the number and types of educational offerings, and whether they are required or elective. The individual presentations were prepared according to a standard template and a list of resources was developed. These resources and presentations, as well 